\title{
A COMMENT ON INCUBATING MALE FALCONS
}

PAUL C. JAMES, Saskatchewan Museum of Natural History, Wascana Park, Regina,

A recent article in the Blue Jay recorded the participation of a male American Kestrel in incubation duties. ${ }^{2}$ I would like to point out that the photograph accompanying the piece shows a female on the nest and not a male. The tail of the bird shown has typical female multiple banding and not the single terminal band of a male. ${ }^{3}$ Male falcons, however, do incubate, but their participation is quite variable both within and among species. ${ }^{1}$ For example, males seldom incubate at night and in species where the male is much smaller than the female, it may be difficult for him to adequately warm the eggs for any extended period of time. Typically, the male's role is to relieve the female for short periods, during which she feeds or performs other activities. Even for short periods, it is not unusual for the male to spend up to one-third of the daylight hours on the eggs.

1. CADE, T.J. 1982. The falcons of the world. Comell University.

2. EVERITT, R. 1991. Male kestrel shares incubating duties. Blue Jay 49:75.

3. NATIONAL GEOGRAPHIC SOCIETY. 1987. Field guide to the birds of North America.

Mechanized recreation has seized nine-tenths of the woods and mountains; a decent respect for minorities should dedicate the other tenth for wilderness. Aldo Leopold, 1949. A Sand County Almanac. Oxford.

The cult of the snake is as ancient as it is widespread. An earth goddess, dating back to $1600-1500$ B.C., with ... a snake in each hand, was found in Crete in the Palace of Knossos... In West Africa under French colonial rule, fifty snakes were kept in a serpent temple in Dahomey (Benin). So sacred were these pythons that to kill one even outside the temple precincts was punishable by death. Dennis Bardens, 1987. Psychic Animals. Holt, N.Y. 


\section{AUTUMN IN SASKATCHEWAN A Photo Essay}

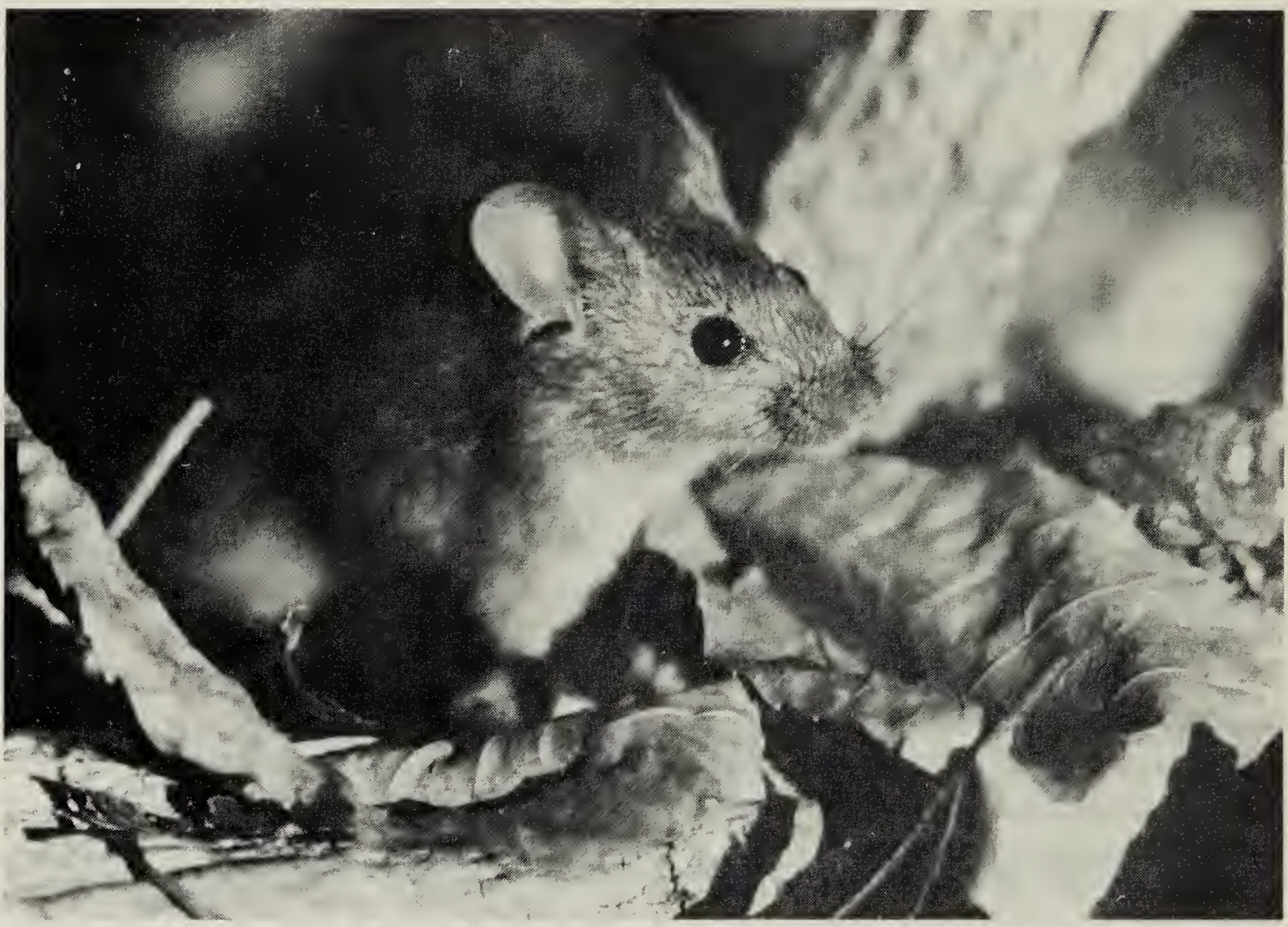

Deer Mouse

Wayne Lynch

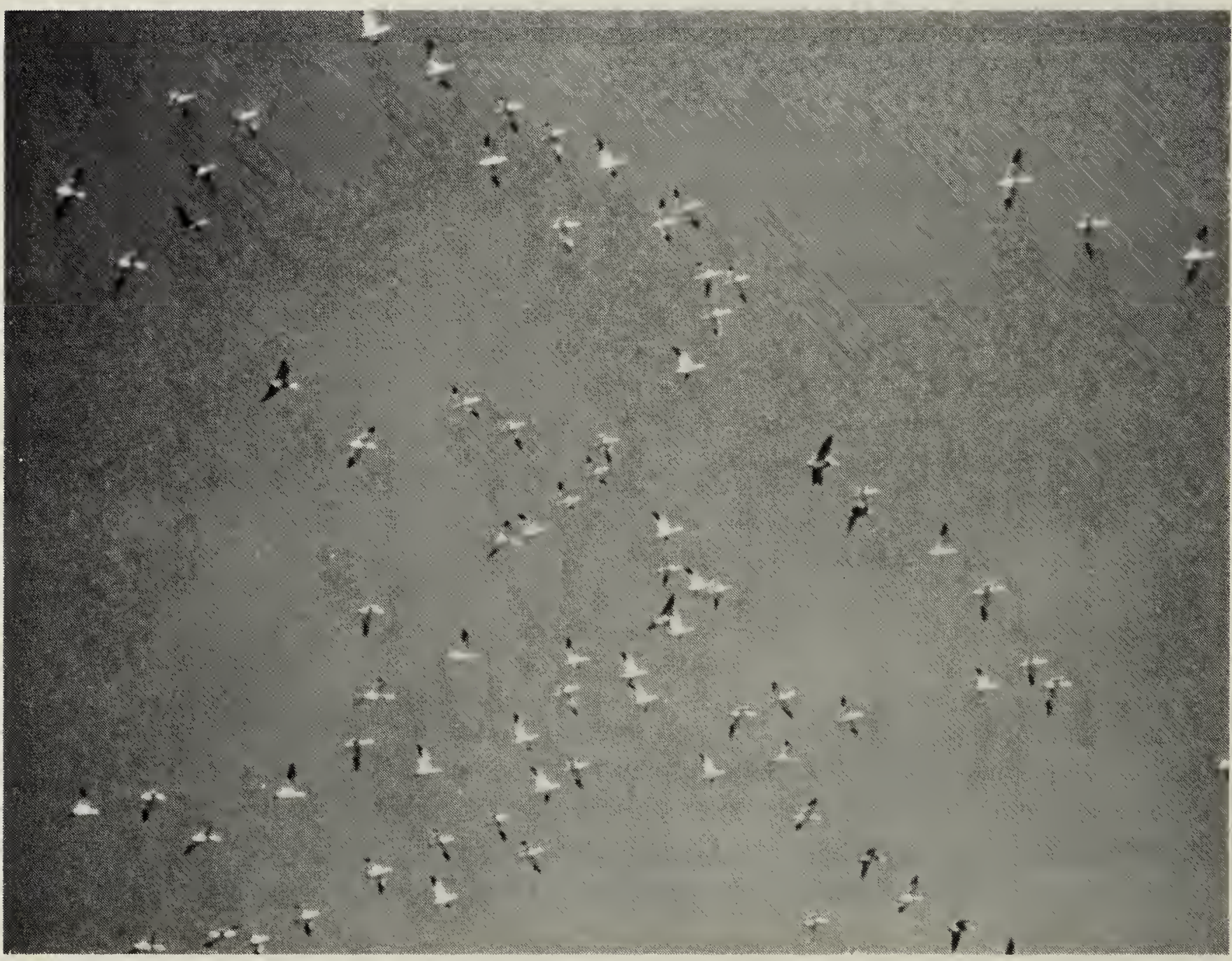




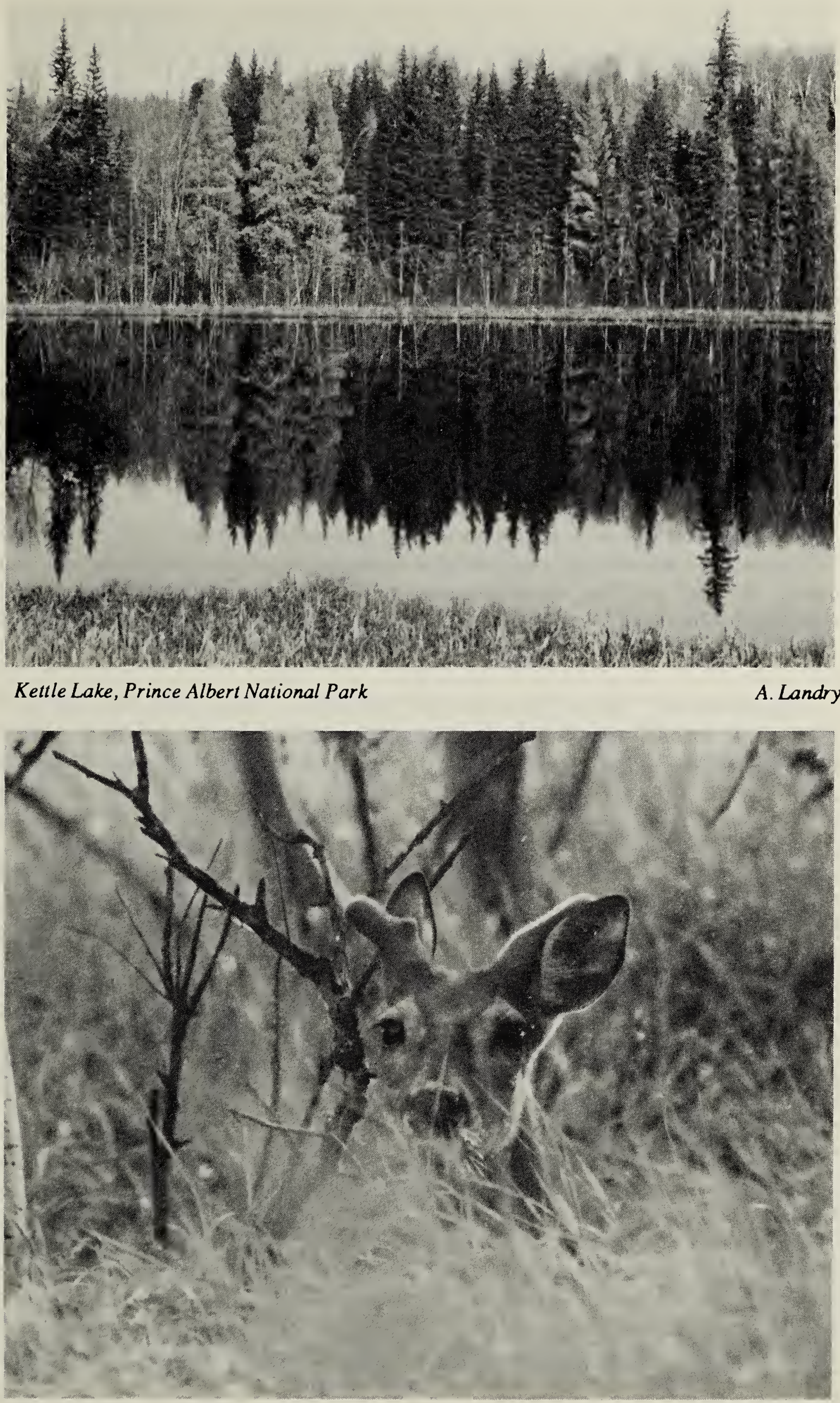

White-Tailed Deer near Chelan, Sask.

Four Winds 